\title{
CRONICA DE LA VIII SEMANA DE ESTUDIOS SUPERIORES DE URBANISMO
}

71

por

\author{
Dionisio Sánchez Fernández de Gatta \\ Profesor Ayudante del Departamento de Derecho Administrativo \\ de la Facultad de Derecho de Salamanca
}

Durante los días 25 a 29 del pasado mes de abril se celebró en Granada la VIII Semana de Estudios Superiores de Urbanismo, convocada por el Instituto de Estudios de Administración Local, en colaboración con el Centro de Estudios Municipales y de Cooperación Interprovincial de las Excelentísimas Diputaciones provinciales de Almería, Granada y Jaén (Delegación Interprovincial del IEAL en Granada), cuyo tema de estudio fue, esta vez, «La propiedad urbana», impartida por profesores, arquitectos y abogados, para alumnos, en su mayoría, funcionarios de la Administración local.

La Semana de Estudios estaba estructurada en dos sesiones diarias de mañana y tarde, suscitándose coloquios, después de cada lección, con problemas propios de la vida diaria de la Administración local.

Las dos primeras lecciones las impartió el catedrático de Derecho administrativo de la Facultad de Derecho de Granada profesor don Eduardo RocA RocA, sobre «La propiedad urbana» y "La revisión de los Planes y la responsabilidad de la Administración..

Comenzó su lección sobre «La propiedad urbana» enmarcándola en su evolución, partiendo del concepto individualista de propiedad 
del Código civil (arts. 348 y 350, principalmente), para llegar a nuestros días, en que, a partir de la Ley del Suelo de 1956, se la considera función pública, diferenciándose el tratamiento del suelo y el de la edificación. Respecto al suelo, constató el profesor Roca su aumento de importancia paralelo al crecimiento de la ciudad, realizando la Administración los servicios necesarios (de sanidad, viales, etc.) para la vida ciudadana, con la participación de la misma Administración en los aumentos de valor del suelo que traen consigo, dado que es la comunidad (representada por la Administración) la que provoca ese aumento.

A continuación se refirió al concepto actual de propiedad urbanística, derivado del derecho constitucional de propiedad (art. $33 \mathrm{de}$ la Constitución), con un contenido delimitado por su función social y configurado con un nuevo estatuto jurídico ya desde la Ley del Suelo de 1956, en que dejó de ser un derecho individualista (artículo $350 \mathrm{CC}$ ) para convertirse en un derecho limitado en su contenido a lo que la Ley urbanística y los Planes de ordenación determinan en cada caso y sujeto, en su ejercicio, al cumplimiento de los deberes específicos que esa Ley y los Planes imponen a su titular (artículo 76 de la Ley del Suelo de 1976), deberes y limitaciones que configuran el contenido normal de la propiedad (art. 87 LS), con lo cual el derecho de propiedad ya no es ilimitado, sino que habrá de ejercitarse conforme a la Ley del Suelo y a los Planes contenidos en ella.

Para terminar esta lección, el profesor RocA planteó la regulación de ese derecho de propiedad, dado que el artículo $53,10^{\circ}, \mathrm{CE}$ hace necesaria una Ley formal, y la posible incidencia de los Planes, como actos normativos sobre el mismo. Señaló que el Planeamiento no regula esa propiedad, pues al ser los Planes actos normativos se produciría una deslegalización que no permite el artículo $53 \mathrm{CE}$; los límites, como contenido normal de la propiedad, provienen de la Ley del Suelo, y los Planes los hacen valer.

En su segunda lección, el profesor Roca estudió «La revisión de los Planes y la responsabilidad de la Administración». Tomó como punto de partida la vigencia indefinida de los Planes, como actos normativos que son (arts. 45 LS y 154, 1., RPU), unida a la posibilidad de revisarlos y modificarlos con el tiempo (arts. 45 a 51 LS), planteando inmediatamente la posible afectación de esas modificaciones o revisiones al contenido del derecho de propiedad, traspa- 
sando su cometido, con la consiguiente responsabilidad de la Administración, en determinados casos.

Distinguió la revisión de la modificación, como instituciones que no pueden ser unidas, como hace la sentencia del Tribunal Supremo de 13 de enero de 1978 (Ar. 157).

A continuación se refirió a las revisiones y modificaciones de Planes que afecten a las zonas verdes y a los espacios libres (artículo 50 LS), estimando que el procedimiento establecido en ese artículo se debe aplicar a ambas, y teniendo en cuenta que ha de haber una disminución real de las zonas y los espacios.

La cuestión siguiente fue la indemnización por daños a derechos adquiridos o intereses legítimos a causa de revisiones o modificaciones del Planeamiento (art. 87 LS), distinguiendo tres casos:

a) Modificación y revisión de Planes redactados a partir de la Ley de Reforma de 1975 y del Texto Refundido de 1976 (art. 87, 2., de la Ley del Suelo), que hacen nacer el derecho a la indemnización si se cumplen los siguientes requisitos:

1) Existencia de un Plan parcial, Plan especial o Programa de Actuación urbanística que establezcan una ordenación de terrenos y construcciones con un determinado aprovechamiento.

2) Que se revisen o modifiquen en uno de estos casos:

- antes de transcurrir los plazos de ejecución;

- si hubiesen transcurrido éstos y la ejecución no se haya llevado a efecto por causas imputables a la Administración.

3) Existencia del derecho adquirido o del interés legítimo y no meras expectativas (STS 29-9-1980, Ar. 3463), utilizando como criterios para determinar ese momento los siguientes:

- realización de la reparcelación (STS 29-9-1980, Ar. 3463, y de 19-9-1981, Ar. 3532);

- haberse realizado la urbanización (STS 1-2-1982, Ar. 773);

- que el titular haya solicitado, en los plazos previstos en el Plan, la licencia de obra nueva.

b) Responsabilidad por la imposición de vinculaciones o limitaciones singulares que lleven consigo una restriccion del aprovecha- 
miento urbanístico del suelo que no pueda ser objeto de distribución equitativa entre los interesados (art. 87, 3.․, LS).

c) Aplicación del régimen de responsabilidad de la Administración en el período transitorio derivado de la Ley de Reforma de 1975.

Partiendo de la complejidad del Derecho transitorio, el profesor Roca suscitó la cuestión de si era aplicable el artículo $87,2 .^{\circ}$, LS a los Planes comprendidos en ese período transitorio, ya que ese supuesto, al ser una determinación legal en la que el Planeamiento es capital, precisa de la existencia de ese mismo Planeamiento (previsto en el texto legal), y señalando las posturas doctrinales existentes (GómEz-FERRER, que aplica a esos Planes el art. 70 LS de 1956; Perales MadueÑo, que aplica el art. $87,2 .^{\circ}$, de la LS vigente, y FerNÁNDEZ RODRfGUEZ, que estima no aplicable este último entretanto no existan los Planes previstos en la vigente Ley, ya que este precepto es la contrapartida a los mayores rigores del régimen del derecho de propiedad y sistema de Planeamiento establecidos por dicha Ley, aunque la adaptación del Planeamiento a la nueva Ley supone el cumplimiento de un mandato legal, por el cual no cabe imputar responsabilidad a la Administración), distingue, según las. Disposiciones transitorias de la Ley del Suelo, los siguientes casos:

1) Planes parciales aprobados antes del 22 de mayo de 1975 (entrada en vigor de la Ley de Reforma) que no estuviesen en ejecución en ese momento. Dado que su ejecución se rige por la nueva Ley (DT 2. ${ }^{\mathrm{a}}$ LS), su alteración anticipada sí dará derecho a indemnización, al ser consecuencia obligada de la aplicación del nuevo régimen, con sus mayores rigores.

2) Planes parciales aprobados definitivamente después del 22 de mayo de 1975, con el mismo argumento, y aceptando la aplicación del artículo 87.

3) Planes parciales en curso de ejecución el 22 de mayo de 1975 , para los cuales la DT 3. ${ }^{a}$ LS prescribe la aplicación de la Ley de 1956.

4) Planes parciales ya ejecutados o cuyo periodo de ejecución haya caducado, que no confieren derecho de indemnización alguno.

Las dos lecciones del segundo día estuvieron a cargo de don $\mathrm{Fe}$ derico LARIos TABUENCA, Oficial Mayor de la Excelentísima Dipu- 
tación de Alicante, y de don Javier GaRcía-Bellmo, Director del Centro de Estudios Urbanos del IEAL.

El señor LARIOS TABUENCA habló sobre «Las cesiones obligatorias y gratuitas de los terrenos por razón de urbanismo». Comenzó resaltando la importancia de un Planeamiento claro, que evite problemas sobre la titularidad a que se destina el suelo, ya que, aclarada ésta, será entonces el momento de obtener suelo mediante las cesiones.

Se refirió, en primer lugar, a la obtención del suelo necesario para los sistemas generales (comunicaciones, espacios libres y equipamiento comunitario: art. $25 \mathrm{RP}$ ) en los Planes generales, distinguiendo:

a) Obligación de cesión de los propietarios de suelo urbano (artículo 83, 3., 1, LS). El señor LARJos estimo preferibles, como medios de adquisición del suelo cedido por la Administración, la expropiación (arts. 134, 2. ${ }^{\circ}$, LS; 55 y 197 ss RP) o la compensación a los propietarios con otros terrenos, a las transferencias de aprovechamiento, por ser complejas, o a las reparcelaciones con unidad discontinua (art. $78,3 .^{\circ}, \mathrm{RG}$ ), por ser lentas y plantear problemas con terceros propietarios.

b) Obligaciones de cesión de los propietarios de suelo urbanizable:

1) Programado (art. $84,3 .^{\circ}, a$, LS), resaltando la mayor amplitud de esta cesión a la anterior. La adquisición también puede producirse por expropiación o por compensación (art. 51 RG), resaltando que el aprovechamiento a tener en cuenta es el 90 por 100 del aprovechamiento medio, con la posibilidad de producirse tratamientos distintos a propietarios de sectores que no superen el aprovechamiento medio del suelo urbanizable programado.

2) No programado: Las cesiones se determinan en las bases del Programa de Actuación urbanística, siendo mayores que las dos anteriores (arts. 146, 3., LS y 219, 2., RG), llamando la atención sobre las conexiones de redes (viaria, agua, etc.) de la zona de actuación y del exterior, por la posibilidad de afectar a la equidad, al poder utilizarse la expropiación (artículos 123 y 152 LS y 224 y 226 RG). 
A continuación examinó estas mismas cesiones en las Normas Subsidiarias Municipales (de tipo $b$, art. $91 \mathrm{RP}$ ), cuya diferenciación respecto a las de los Planes generales radica en el suelo apto para urbanizar, por no aplicarse el apartado $b$ ) del párrafo tercero del artículo 46 RG (exceso de aprovechamiento: art. 57 RG), al no existir cálculo de aprovechamiento medio; reflexionando, al mismo tiempo, sobre la importancia de la obtención del suelo para los sistemas generales en la elección de la figura de Planeamiento.

La cuestión siguiente fue la legitimación de las cesiones que produce el Planeamiento, siendo, en suelo urbano, el Plan general, al ser muy detallista (art. 31, $1^{\circ}, \mathrm{RG}$ ), y en las demás clases de suelo, el Plan parcial (arts. $31,2^{\circ}$ y $3 .^{\circ}$, y $32 \mathrm{RG}$ ), resaltando la importancia de respetar el principio de jerarquía urbanística, no aceptando, por consiguiente, que se puedan legitimar las cesiones mediante licencias.

El último punto tratado fue la cesión del 10 por 100 del aprovechamiento medio (arts. 84 y 85 LS y 57 RG, según la clase de suelo y el instrumento de Planeamiento). No estimó muy aceptable la posibilidad que la Entidad actuante tiene de sustituir esa obligación por otras mayores (arts. 146 LS y 219 RG), porque se pueden producir perjuicios para la Administración. Terminó comentando el problema de si ese 10 por 100 cedido ha de entregarse urbanizado o no, en el sistema de compensación, aplicándole el artículo 186 RG, a pesar de referirse al sistema de cooperación, pudiéndose, por tanto, repercutir los costos en esa proporción.

La lección de don Javier GARcta-BELLIDo fue sobre «Los métodos de Planeamiento urbano", cuyos puntos de análisis fueron la configuración del suelo urbano en su estructura económica, debido a la renta diferencial y a la de aprovechamiento, lo que le ha producido una cristalización de valores concretos económicos; después, comentó las características de las actuaciones de los propietarios en este suelo (discontinuas en el espacio, fraccionadas y pequeñas, forma asistemática e incremental, competitivas, etc.) y las técnicas de Planeamiento utilizadas hasta ahora (abuso del "fuera de ordenación", catalogación o no de los edificios, influencia del automóvil-viales en el Planeamiento y el concepto de ruina), terminando con los modos de actuación futura, que basó en el principio de conservación, distinguiendo la de edificios (con conservación del edificio y de su uso), mediante la no incentivación a las demoliciones y la catalogación por conjuntos, y la conservación de la ciudad como un todo, mediante acciones como no aumentar los volúmenes y las alturas exis- 
tentes, potenciar los equipamientos, mantener los usos públicos, establecer un aprovechamiento único (tipo) por zonas homogéneas de la ciudad, etc.

Las conferencias del día siguiente estuvieron a cargo de don $\mathrm{Fe}$ derico LaRios Tabuenca y de don Antonio TASTET Diaz, Abogado.

Don Federico LARIos TABUENCA se refirió esta vez a «La parcelación de fincas rústicas con fines urbanísticos», comenzando con una introducción, para fijar el tema en lo relativo a la segunda residencia y a su falta de equipamiento, y a la obtención de beneficios injustificados por la especulación con el suelo no urbanizable.

La protección de los recursos naturales, incluido el suelo, fue el punto tratado inmediatamente, partiendo del artículo $45 \mathrm{CE}$, que regula el derecho al medio ambiente y la utilización racional de los recursos naturales, pasando por los Planes directores territoriales de coordinación (arts. 8., 11 y 12 LS) y los Planes generales, en que estudió el concepto de suelo no urbanizable (arts. 77 y 80 LS y 24 RP), criticando su carácter residual (ya que este suelo tiene la misma entidad que los otros), y el término "excepcional» del artículo 80,b), de la Ley del Suelo, por ser un concepto jurídico indeterminado; terminando con los Planes especiales, como desarrollo de Planes generales (arts. 17, 19 y 21 LS) o sin tener ese carácter (art. 76, 3. , RP, del cual se ha dudado su legalidad), y las normas de aplicación directa (arts. 73 LS y 98 RP), a cuya aplicación es remisa la Jurisprudencia por existir otros instrumentos protectores del suelo no urbanizable, como hemos visto.

Después de detenerse en la limitación de usos de que es objeto este suelo, pasó a estudiar las parcelaciones del mismo, haciendo un análisis del Reglamento de Servicios de 1955, la Ley del Suelo de 1956, el Reglamento de Reparcelaciones y el Proyecto de Ley de Reforma de la Ley del Suelo de 1972, respecto al concepto de parcelación.

Con esto inició el análisis del texto vigente, de 1976, por el concepto del artículo 94, deteniéndose en sus criterios sobre todo en el concepto de núcleo de población, que estudió a través de su regulación legal (arts. 34, $d ; 36, b ; 90, c ; 92, c ; 93, c$, RP, incluyendo la Ley del Parlamento de Cataluña de 18-11-1981, sobre Protección de la Legalidad urbanística), con ejemplos concretos (campings, caravanas, etcétera). En conexión con este punto, se refirió a las conexiones entre el Derecho urbanístico y el Derecho agrario, en orden a determinar la extensión de las parcelas para urbanizar, en relación con 
la unidad mínima de cultivo, como protección a la excesiva parcelación de este suelo.

Seguidamente se ocupó, de nuevo, del concepto de suelo no urbanizable (arts. 77 y 80 LS), deteniéndose en sus usos (normales o agrícolas y no agrícolas), de los que depende la obligatoriedad de la parcelación (en este último caso, con ejemplos). Para terminar analizando las parcelaciones ilegales y sus sanciones.

Don Antonio TASTET Díaz estudió el «Régimen de las urbanizaciones privadas». Estimó el Plan parcial como el más adecuado a estas urbanizaciones, aunque la iniciativa privada pueda elaborar otros Planes (art. 52 LS), resaltando la importancia de respetar el principio de jerarquía del Planeamiento (trasunto del de jerarquía normativa) y el interés público, aunque reconociendo sus dificultades, al chocar con el interés de los particulares redactores del Plan. A continuación pasó revista a la tramitación del Plan, deteniéndose en la obligatoriedad de la notificación a los propietarios afectados (artículo $139,2^{\circ}, \mathrm{RP}$ ), en la no existencia de la suspensión de licencias, ya que no cabe, en la posibilidad de que el acto de aprobación, provisional y definitiva, imponga condiciones (art. 139, 3., $\mathrm{RP}$ ), y, por último, en la obligatoriedad de la prestación de la garantía, previa a la publicación del acuerdo de aprobación (art. 139, 3., RP).

Para terminar esta lección, pasó revista a determinados problemas concretos relacionados con el tema: titularidad de los viales de estas urbanizaciones, aprovechamiento medio, no urbanización, a pesar de haber acabado la tramitación; modificación del Plan parcial, etc., todos con ejemplos jurisprudenciales.

En la siguiente sesión, de nuevo, habló el señor TASTET Dfaz, esta vez sobre las "Ordenes de ejecución", distinguiendo el estudio de los artículos 181 LS (órdenes de ejecución de obras, para conservar la seguridad, salubridad y ornato públicos, de carteles, edificios, urbanizaciones de iniciativa particular y terrenos), 182 LS (órdenes por causa de interés turístico o estético) y 183 LS (órdenes relacionadas con el estado ruinoso de construcciones o de parte de ellas), dividiéndolo en elementos subjetivos, objetivos, teleológicos y formales, suscitándose, en el caso del artículo 181, el problema que supone la dilación de la orden, hasta la resolución del expediente sancionador correspondiente, por no haberse realizado las obras de conservación ordenadas (art. 10, 3. , RDU).

«La rehabilitación integrada del Patrimonio arquitectónico» fue el tema de la conferencia de doña Amparo Precroso, Subdirectora 
general de Arquitectura del Ministerio de Obras Públicas y Urbanismo, que planteó temas como la excesiva legislación existente sobre el campo de la rehabilitación; el nivel competencial, haciendo recaer sobre el Municipio gran parte del mismo, al ser el más cercano al problema, aunque estimó no debe ser el único, si bien puede tener facultades coordinadoras; consideró las subvenciones mejor medio de ayuda que primar la financiación; la agilización del procedimiento administrativo y las viviendas rurales, entre los más importantes.

La sesión de clausura estuvo dividida entre don Francisco PoL, Arquitecto y Director del Programa piloto de Rehabilitación de la manzana de Cascorro, en Madrid, y don Emilio Molina, Director general de Urbanismo de la Junta de Andalucía.

Don Francisco Pol habló sobre "Las condiciones técnicas y financieras para la rehabilitación de viviendas», refiriéndose al marco general de la política de rehabilitación y al caso de Madrid.

Como objetivos de la política de rehabilitación, señaló su extensión a todo el patrimonio urbano y residencial, siendo prioritarios los contenidos sociales, protegiendo a los usuarios actuales, y la racionalidad económica.

Dividió las medidas tendentes a conseguir estos objetivos en directas e indirectas. Las directas implican la intervención pública, mediante la rehabilitación del propio patrimonio público y la adquisición de edificios en los cascos antiguos de las ciudades. Entre las indirectas señaló el fomento financiero público a la iniciativa privada, así como su asesoramiento. Además, consideró importante el descentralizar las acciones, pero potenciando la coordinación de las mismas (por áreas, según las inversiones, etc.) y la investigación tecnológica.

A continuación nos expuso el caso de Madrid, con las acciones llevadas a cabo mediante el Plan especial y ese Programa piloto.

Don Emilio Molina expuso "La ordenación urbanística en Andalucía», en base a las líneas de actuación de la Junta de Andalucía, que son: potenciación y mejora de la Administración urbanística regional (culminación del proceso de transferencias desde el Estado, reorganización de la Administración regional, Proyecto de Ley del Instituto Andaluz del Suelo, coordinación y cooperación con otras Administraciones); fomento del Planeamiento, para cubrir el territorio de la Comunidad Autónoma de forma adecuada; apoyo a la gestión municipal; potenciar la disciplina urbanística (Proyecto 
de Ley de Disciplina urbanística); fomento de la información y participación ciudadana, $y$, por último, mejora de la cualificación de los profesionales relacionados con el urbanismo. Además, consideró poco probable que el Parlamento andaluz legisle modificando la Ley del Suelo, aunque sí estimó posible que legisle sobre puntos concretos (disciplina, directrices territoriales de Andalucía e Instituto del Suelo). 


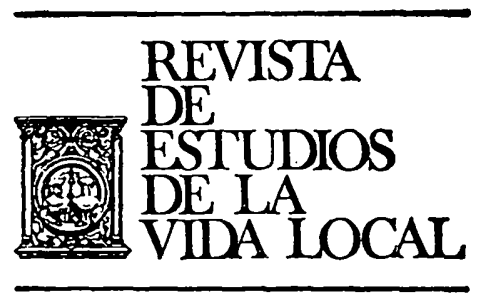

\section{ESTADISTICA}


REVL-1983, núm. 219. SANCHEZ FERNANDEZ DE GATTA, DIONISIO. CRONICA DE LA VIII SE...

REVL-1983, núm. 219. SANCHEZ FERNANDEZ DE GATTA, DIONISIO. CRONICA DE LA VIII SE... 